Article

\title{
Conductive Cotton Filters for Affordable and Efficient Water Purification
}

\author{
Fang Li ${ }^{1,2}$, Qin Xia ${ }^{1}$, Qianxun Cheng ${ }^{1}$, Mingzhi Huang ${ }^{3}$ and Yanbiao Liu ${ }^{1,2, *}$ \\ 1 School of Environmental Science and Engineering, Donghua University, Shanghai 201620, China; \\ lifang@mail.dhu.edu.cn (F.L.); rachel.q.xia@gmail.com (Q.X.); chengqianxun@dhu.edu.cn (Q.C.) \\ 2 Textile Pollution Controlling Engineering Centre of Ministry of Environmental Protection, \\ Shanghai 201620, China \\ 3 Department of Water Resources and Environment, Guangdong Provincial Key Laboratory of Urbanization \\ and Geo-Simulation, Sun Yat-sen University, Guangzhou 510275, China; huangmzh6@mail.sysu.edu.cn \\ * Correspondence: yanbiaoliu@dhu.edu.cn; Tel.: +86-021-67792545
}

Received: 12 September 2017; Accepted: 26 September 2017; Published: 29 September 2017

\begin{abstract}
It is highly desirable to develop affordable, energy-saving, and highly-effective technologies to alleviate the current water crisis. In this work, we reported a low-cost electrochemical filtration device composing of a conductive cotton filter anode and a Ti foil cathode. The device was operated by gravity feed. The conductive cotton filter anodes were fabricated by a facile dying method to incorporate carbon nanotubes (CNTs) as fillers. The CNTs could serve as adsorbents for pollutants adsorption, as electrocatalysts for pollutants electrooxidation, and as conductive additives to render the cotton filters highly conductive. Cellulose-based cotton could serve as low-cost support to 'host' these CNTs. Upon application of external potential, the developed filtration device could not only achieve physically adsorption of organic compounds, but also chemically oxide these compounds on site. Three model organic compounds were employed to evaluate the oxidative capability of the device, i.e., ferrocyanide (a model single-electron-transfer electron donor), methyl orange ( $\mathrm{MO}$, a common recalcitrant azo-dye found in aqueous environments), and antibiotic tetracycline (TC, a common antibiotic released from the wastewater treatment plants). The devices exhibited a maximum electrooxidation flux of $0.37 \mathrm{~mol} / \mathrm{h} / \mathrm{m}^{2}$ for $5.0 \mathrm{mmol} / \mathrm{L}$ ferrocyanide, of $0.26 \mathrm{~mol} / \mathrm{h} / \mathrm{m}^{2}$ for $0.06 \mathrm{mmol} / \mathrm{L} \mathrm{MO}$, and of $0.9 \mathrm{~mol} / \mathrm{h} / \mathrm{m}^{2}$ for $0.2 \mathrm{mmol} / \mathrm{L} \mathrm{TC}$ under given experimental conditions. The effects of several key operational parameters (e.g., total cell potential, CNT amount, and compound concentration) on the device performance were also studied. This study could shed some light on the good design of effective and affordable water purification devices for point-of-use applications.
\end{abstract}

Keywords: conductive cotton filter; carbon nanotubes; low-cost; water purification; gravity feed

\section{Introduction}

One of the grand challenges of 21st century is to provide affordable and clean water to meet human needs. However, rapid industrial development, fast population growth, and global climate change have caused serious water pollution we are currently facing [1]. During the past few decades, numerous efforts have been devoted to developing feasible and sustainable technologies to alleviate the water crisis. To be mentioned are technologies such as membrane separations (e.g., reverse osmosis, RO) [2,3] and advanced oxidation processes (AOPs, e.g., UV-ozone and photocatalysis) [4-8]. Many of them only have limited success. For example, the efficacy of both RO and AOPs could be negatively affected by natural organic matters (NOM) due to membrane fouling and oxidant scavenging $[9,10]$. High energy consumption and high cost also restrict the wide application of other 
promising technologies such as electrodialysis. Therefore, it is highly desirable to develop efficient, affordable, scalable, and energy-saving water treatment devices and technologies.

Electrochemical oxidation has proven to be effective for the decomposition of organic pollutants and the key to this technology is a high-performance electrocatalyst [11-13]. In recent years, carbon-based materials have been widely applied as electrode materials for electrochemical processes. Among these newly developed electrode materials, carbon nanotubes (CNTs) are especially attractive due to their large specific surface area $\left(50-500 \mathrm{~m}^{2} / \mathrm{g}\right)$, excellent electrical conductivity $\left(10^{4}-10^{6} \mathrm{~S} / \mathrm{m}\right)$, and desirable chemical resistivity and stability [14-17]. A highly porous CNT membrane or filter can be easily fabricated via vacuum filtration. These filters can be used for the removal of pollutants by physical adsorption [18]. A electrochemical CNT filter could bring this concept one step further by not only physically adsorb the pollutants but also electrochemically oxide the pollutants in situ [19]. However, most of the reported CNT filters are generally $<10 \mathrm{~cm}$ in diameter and further upscaling of these CNT filters is challenging [20]. Another approach to utilize CNTs is to construct 3D macrostructures. For example, a CNT sponge synthesized by CVD method exhibits excellent rejection performance for several organic solvents and oils with different densities (e.g., ethanol, hexane, ethylene glycol, gasoline, and pump oil) [21]. The harsh synthesis conditions have, however, limited significantly the wide application of this promising design [22]. Also, the CNTs can be used as conductive fillers to boost the electrical conductivity of a designed composite. For example, Schoen et al. previously developed a composite filter material based on three one-dimensional (1D) materials, i.e., silver nanowires, CNTs, and cellulose cotton fibers. The fabricated composite filter could inactivate $>98 \%$ of bacteria within only several seconds via electroporation [23]. To obtain a high-performance CNTs-based composite, an ideal support material is also of significance [24]. Among various support materials reported so far, the cotton-based support has attracted extensive interest from the community due to their desirable characteristics like mechanically and chemically robust, highly porous, readily available, and cheap [25]. Some reported cotton/CNTs composite materials have been used as electrode materials for supercapacitor [26] and sensor applications [27]. To the best of our knowledge, there are very limited reports on the simultaneous adsorption and electro-oxidation of organic pollutants using 3D conductive cotton filters in a continuous flow filtration design.

In this study, an efficient electrochemical water purification technology based on conductive cotton filters was developed. The composite filter can be fabricated via a facile and scalable dying method. In particular, the CNTs served as adsorbents and electrocatalysts for pollutant adsorption and electrooxidation. The device was operated by gravity feed (Figure 1a), so that the operation cost could be further decreased. The performance of the device was evaluated using three selected model compounds, e.g., ferrocyanide (a model single-electron-transfer electron donor), methyl orange (MO, a common recalcitrant azo-dye found in aqueous environments), and antibiotic tetracycline (TC, a common antibiotic released from the wastewater treatment plants). The effects of key operational parameters on the device performance were systematically studied. The details of this investigation presented below. 

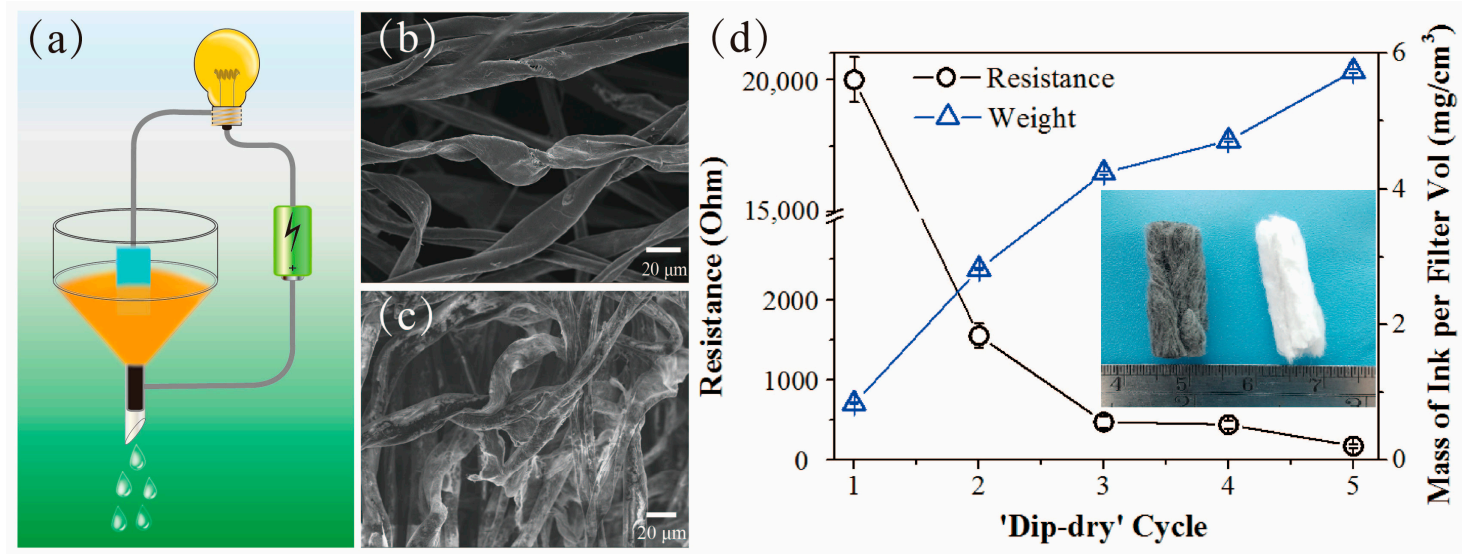

Figure 1. (a) Schematic illustration of the electrochemical cotton filtration device; FESEM images of (b) a pristine cotton and (c) a CNT-coated cotton filter; (d) change of filter resistance and weight of cotton filter as a function of 'dip-dry' cycles. The inset in (d) is digital pictures of a pristine cotton filter (white, right) and a CNT-coated cotton filter (black, left).

\section{Results and Discussion}

\subsection{Fabrication of Conductive Cotton Filters}

The conductive cotton filters were fabricated by a facile dying method. The CNT, SDBS, and cotton are key components for this design. The CNT could serve as high-performance sorbent and electrocatalyst for pollutants adsorption and electrooxidation. It could also facilitate the cotton as a conductive electrode material. Firstly, three different surfactants-polyvinyl pyrrolidone (PVP), sodium dodecyl sulphate (SDS), and SDBS-were employed to disperse CNTs in DI- $\mathrm{H}_{2} \mathrm{O}$. While only $10 \mathrm{mg} \mathrm{mL}^{-1}$ of SDBS could successfully disperse CNTs and a homogeneous solution can be obtained after 15 min probe sonication treatment. Visible agglomerates can be witnessed when using PVP and SDS of the same concentration. This finding suggests that SDBS is an ideal surfactant to facilitate the dispersion of CNT in aqueous solution via $\pi-\pi$ interaction between the SDBS benzene rings and the aromatic structure of CNTs [28]. Thus, SDBS could provide good protection for CNTs to avoid agglomeration. Moreover, the SDBS could serve as a 'bridge' to connect CNTs with cotton, by bonding CNT with benzene ring moieties and bonding with the hydroxyl-groups of cotton cellulose fibers via van der Waals forces and/or hydrogen. The cotton could serve as macro-porous and low-cost support materials to 'host' these CNTs $[29,30]$. The CNTs might interwine each other to further enhance the stability of the as-fabricated 3D cotton filters. In a typical fabrication process, $100 \mathrm{mg}$ cotton sample was immersed into a freshly-prepared CNT ink solution (composed of $1.5 \mathrm{mg} / \mathrm{mL}$ CNTs and $10 \mathrm{mg} / \mathrm{mL}$ SDBS), followed by a drying process at $120^{\circ} \mathrm{C}$ for $30 \mathrm{~min}$ to remove water residue. The inset in Figure $1 \mathrm{~d}$ compares the digital pictures of a pristine cotton (white, right) and a CNT-coated cotton (black, left). The black color provides supportive evidence for the successful CNT loading. Furthermore, field-emission scanning electron microscopy (FESEM) technique was employed to provide detailed morphological information. As displayed in Figure $1 \mathrm{~b}, \mathrm{c}$, the pristine cotton sample showed a twisted and smooth fiber-like structure with an average fiber width of $\sim 50 \mu \mathrm{m}$ and an average pore size of $\sim 110 \mu \mathrm{m}$. However, the surface became much rougher after CNT loading. A magnified image showed that the CNTs were distributed uniformly onto the cellulose fiber surface (Figure S1, Supplementary Materials). This data provides supportive evidence for the successful loading of CNT onto the cotton. Also, by varying the 'dip-dry' cycles and CNT content in the ink, the loading amounts of CNTs onto the cotton as well as the electrical conductivity of the as-fabricated filters can be controlled (Figure S2, Supplementary Materials). For example, as shown in Figure 1d, the accumulated ink mass adsorbed per volume of the cotton increased from $0.85 \mathrm{mg} / \mathrm{cm}^{3}$ (one 'dip-dry' cycle, by dividing the filter weight gain with the filter volume) to $5.74 \mathrm{mg} / \mathrm{cm}^{3}$ (five 'dip-dry' cycles) when using a $1.5 \mathrm{mg} / \mathrm{mL}$ 
CNT ink. This indicates a quantitative sorption of conductive nanotubes onto the cotton surface. Meanwhile, as expected, the sheet resistance of the cotton filter samples decreased significantly from $20,000 \pm 850 \Omega$ to $170 \pm 30 \Omega$, mainly due to the continuous increase of highly conductive CNTs within the cotton filters. As a simple demonstration of the electrical conductivity, an LED lamp connected to a direct current (DC) power supply ( $4.0 \mathrm{~V}$ applied voltage) can be easily powered through the as-fabricated conductive cotton filters (Figure S3, Supplementary Materials). Given that the CNT loading amount became rather limited over five 'dip-dry' cycles, hence, this number was chosen for all subsequent experiments.

\subsection{Electron Transfer}

The electrochemical performance of a conductive cotton filter was firstly evaluated using ferrocyanide $\left(\mathrm{F}_{\mathrm{e}}(\mathrm{CN})_{6}^{4-}\right)$ as model electron donor. The unique characteristics of single-electron transfer and negligible adsorption of ferrocyanide make it suitable candidate for electron transfer experiment [31,32]. The oxidation of ferrocyanide can be described by Equation (1).

$$
\mathrm{Fe}(\mathrm{CN})_{6}^{3-}+\mathrm{e}^{-} \rightarrow \mathrm{Fe}(\mathrm{CN})_{6}^{4-}, E_{0}=0.139 \mathrm{~V} \text { vs. } \mathrm{Ag} / \mathrm{AgCl}
$$

Figure 2 shows the change of electrooxidation flux of ferrocyanide as a function of applied anode potential and ferrocyanide concentrations. At an anode potential range of $0.15-0.4 \mathrm{~V}(\mathrm{vs} . \mathrm{Ag} / \mathrm{AgCl})$, a linear relationship between electrooxidation flux of ferrocyanide and applied anode potential can be observed for all influent concentrations. Voltage-independent plateaus were achieved for all cases when anode potential above $0.4 \mathrm{~V}$ (vs. $\mathrm{Ag} / \mathrm{AgCl}$ ). This finding indicates the mass transport limitations. At an anode potential of $0.4 \mathrm{~V}$, the electrooxidation rate of ferrocyanide was $0.037,0.106,0.145$, and $0.373 \mathrm{~mol} / \mathrm{h} / \mathrm{m}^{2}$ for $0.2,0.5,1.0$, and $5.0 \mathrm{mmol} / \mathrm{L}$ ferrocyanide, respectively. The electrooxidation flux increased up to 10-fold by increasing the influent concentration and interval electrode convection. This value was lower than a reported graphene-CNT composite filter (e.g., 15-fold) [32]. The reason may be due to a much thinner thickness of the graphene-CNT filter $(10 \mu \mathrm{m} v \mathrm{~s} .2 .5 \mathrm{~cm})$ and, hence, an increased transport resistance of ferrocyanide ions in the current design. As only one electron transfer was involved to oxide ferrocyanide to ferricyanide, the maximum electron transfers at an applied anode potential of $0.4 \mathrm{~V}$ (vs. Ag/ AgCl) were calculated to be $1 \times 10^{14}, 3 \times 10^{14}, 1 \times 10^{15} \mathrm{e} / \mathrm{s}$ for $0.2,0.5,1.0$, and $5.0 \mathrm{mmol} / \mathrm{L}$ ferrocyanide, respectively.

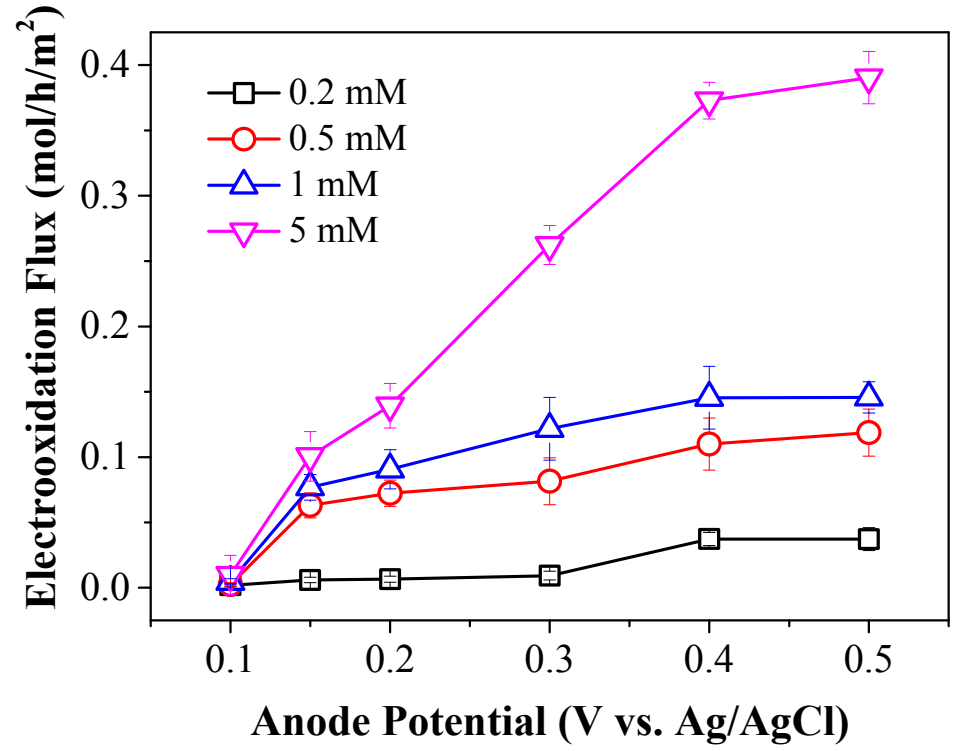

Figure 2. Concentration-dependent oxidation of ferrocyanide using an electrochemical cotton filter. Experimental conditions: $[\mathrm{CNT}]_{\text {ink }}=1.5 \mathrm{mg} / \mathrm{mL},\left[\mathrm{Na}_{2} \mathrm{SO}_{4}\right]=10 \mathrm{mmol} / \mathrm{L}$, and flow rate $=1.5 \mathrm{~mL} / \mathrm{min}$. 


\subsection{Performance of the Cotton Filter towards MO Removal}

To further evaluate the feasibility of the as-fabricated conductive cotton filters for organic pollutants degradation, methyl orange (MO) was selected as a typical recalcitrant organic compound in aqueous environment. Firstly, the $\mathrm{MO}$ sorption process on a conductive cotton filter was examined by breakthrough curve analysis in the absence of electrochemistry. As displayed in Figure S4 (Supplementary Materials), the sorption behavior of cotton filters fabricated with different CNT concentrations varies significantly. The effluent $\mathrm{MO}$ concentration flow through the cotton filters fabricated by a $0.5 \mathrm{mg} / \mathrm{mL}$ and a $1.0 \mathrm{mg} / \mathrm{mL}$ CNT ink solution increased sharply at the initial $5-10 \mathrm{~min}$ and then maintained a stable concentration. For the cotton filter fabricated by a $1.5 \mathrm{mg} / \mathrm{mL} \mathrm{CNT}$ ink, the effluent increased at a gentle slope in the first $18 \mathrm{~min}$ and then showed a steeper increase before breakthrough occurs. The cotton filter MO sorption capacity was $53.5 \mathrm{mg} / \mathrm{g}, 1.8$ times higher than a pure CNT filter reported previously [33]. This increased sorption capacity observed in this study are likely due to the contribution of MO sorption by the cotton support. However, the limited area of the cotton filter results in an absolute sorption capacity that is relatively low and in turn $\mathrm{MO}$ breakthrough occurs within $1 \mathrm{~h}$. Thus, further experiments were conducted to electrochemically degrade the adsorbed MO molecules and to regenerate adsorption sites.

The electrooxidative filtration of MO was evaluated as a function of total cell potential and CNT loading onto the cotton filters as displayed in Figure 3a. The MO oxidation flux increased with increasing total cell potential to a maximum of $0.26 \pm 0.02 \mathrm{~mol} / \mathrm{h} / \mathrm{m}^{2}$ at $3.5 \mathrm{~V}$ for the cotton filter fabricated using a $1.5 \mathrm{mg} / \mathrm{mL} \mathrm{CNT}$ ink. Further increase of the total cell potential to $4.0 \mathrm{~V}$ did not improve the device performance due to other side reactions (e.g., water oxidation) occurred at this condition, resulting in the loss of electrochemical activity. Moreover, increased electrolytic gas bubble formation at a higher potential may block some active sites on the filter surface, or even degrade the filter integrity to some extent. It is of note that the optimal total cell potential of $3.5 \mathrm{~V}$ for $\mathrm{MO}$ electrooxidation was higher than that of a CNT electrochemical filter (e.g., 2.5 V). This difference may be due to an increased filter resistance $(\sim 175 \Omega$ vs. $\sim 50 \Omega)$ and a reduced CNT content $(\sim 7 \mathrm{mg}$ vs. $30 \mathrm{mg})$ of the cotton filters reported in this work. The increased resistance of the as-fabricated cotton filters may increase the resistance for the transport of electrons, so that an increased overpotential may be needed to overcome this barrier. Moreover, the CNT content in the ink is another important factor for the electro-oxidative process. As expected, the MO electrooxidation flux was increased with CNT amount for all cases. For example, at a given total cell potential of $3.5 \mathrm{~V}$, the MO electrooxidation flux was $0.15,0.23$, and $0.26 \mathrm{~mol} / \mathrm{h} / \mathrm{m}^{2}$ for CNT ink concentration of $0.5 \mathrm{mg} / \mathrm{mL}, 1.0 \mathrm{mg} / \mathrm{mL}$, and $1.5 \mathrm{mg} / \mathrm{mL}$, respectively. Since more CNT loading will lead to more active sites for the sorption and electrooxidation of MO molecules and increase the electrical conductivity of the as-fabricated filters (or decreased electron transport resistance). The $0.26 \mathrm{~mol} / \mathrm{h} / \mathrm{m}^{2}$ electrooxidation flux of $\mathrm{MO}$ in a single pass through the cotton filter is of note since the device was running by gravity feed. These data suggest the potential of a cost-effective, energy-saving, and facile method for the efficient removal of organic compounds from water.

Open circuit potential measurements over a range of cell potentials for the device was conducted with a cotton filter anode, a Ti cathode, $[\mathrm{MO}]_{\text {in }}=0.06 \mathrm{mmol} / \mathrm{L}$ and $\left[\mathrm{Na}_{2} \mathrm{SO}_{4}\right]=10 \mathrm{mmol} / \mathrm{L}$. As shown in Figure $3 \mathrm{~b}$, a total cell potential of $3.0 \mathrm{~V}$ was required to achieve a high enough anode potential $(>+0.8 \mathrm{~V}$ vs. $\mathrm{Ag} / \mathrm{AgCl}$ ) for $\mathrm{MO}$ oxidation as determined by the cyclic voltammogram measurement [33]. At a total cell potential of $4 \mathrm{~V}$, the anode potential was as high as $1.5 \mathrm{~V}$ vs. $\mathrm{Ag} / \mathrm{AgCl}$ which has exceeded the water oxidation potential of $1.23 \mathrm{~V}$ (vs. standard hydrogen electrode, SHE). This finding supports the change of MO electrooxidation flux with total cell potential as shown in Figure 3a.

The re-usability of the cotton filters is of great significance towards practical applications. Hence, additional experiments to evaluate the regeneration performance of the cotton filters were conducted. As shown in Figure 3c, the cotton filter exhibits an initial MO oxidation flux of $0.27 \mathrm{~mol} / \mathrm{h} / \mathrm{m}^{2}$ and a MO removal efficiency of $>98 \%$ in the first $30 \mathrm{~min}$, which then slightly decreased in the following few hours. The decrement in MO oxidation can be due to the MO oxidation byproducts and/or 
precipitates accumulated onto the filter surface. This hypothesis was further confirmed by the SEM characterization results of the cotton filter after running. As shown in the inset, certain polydispersed nanoparticles and/or precipitates were observed on the cotton surface that might eventually foul the cotton filter. These materials could be organic polymers and/or inorganic sodium persulfate [34]. The build-up of polymer/precipitates may cause some adverse effects on the oxidative performance of the filter by blocking the active centers of the filter, significantly increasing resistance to water and electron transfer, thus reducing the reaction kinetics and electrochemistry. To eliminate the contribution of MO degradation by the possibly produced persulfate precipitates, another control experiment was conducted by mixing $0.1-5 \mathrm{mmol} / \mathrm{L}$ persulfate with $0.06 \mathrm{mmol} / \mathrm{L} \mathrm{MO}$. The results show that the MO concentration changed negligible $(<0.4 \%)$ for all cases. This finding supports the conclusion that the MO removal was mainly due to the electrooxidation by the filter. A $100 \mathrm{~mL}$ of $1 \mathrm{~mol} / \mathrm{L} \mathrm{HCl}$ : ethanol mixture (50:50 vol \%) washing of the cotton filter was found to be effective to restore the initial electrooxidation flux. An average electrooxidation flux of $0.2 \mathrm{~mol} / \mathrm{h} / \mathrm{m}^{2}$ was achieved for the next two running cycles. Also, the lack of breakthrough during the $8 \mathrm{~h}$ continuous running at $3.5 \mathrm{~V}$ total cell potential suggests that the primary removal mechanism during electrochemical filtration is oxidative degradation rather than physical adsorption. These data suggest the potential of a cost-effective, energy-saving, and facile method for the efficient removal of organic compounds from water.

(a)

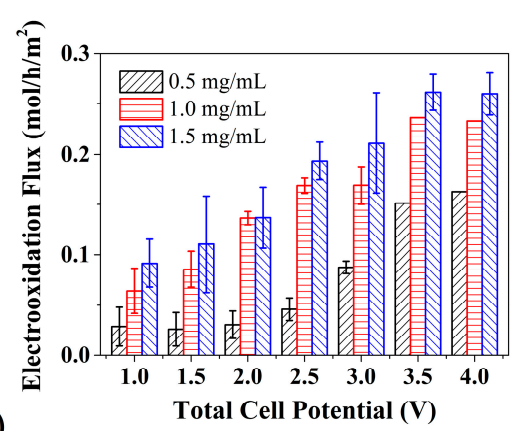

(b)

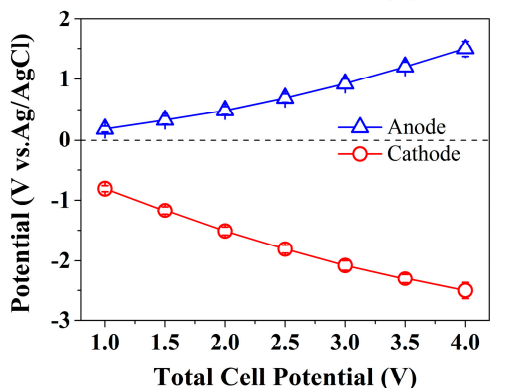

(c)

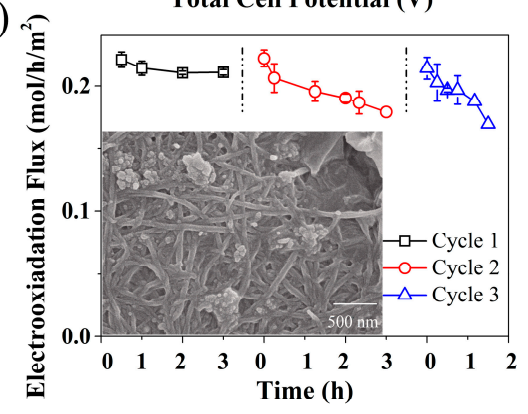

Figure 3. MO electrooxidation flux (a) and open-circuit potential (b) as a functional total cell potential. Experimental conditions: $\left[\mathrm{MO}_{\text {in }}=0.06 \mathrm{mmol} / \mathrm{L},\left[\mathrm{Na}_{2} \mathrm{SO}_{4}\right]=10 \mathrm{mmol} / \mathrm{L},[\mathrm{CNT}]_{\text {ink }}=1.5 \mathrm{mg} / \mathrm{mL}\right.$, and flow rate $=1.5 \mathrm{~mL} / \mathrm{min}$; The regeneration performance of a cotton filter. The filter was washed with a $100 \mathrm{~mL}$ of $1 \mathrm{~mol} / \mathrm{L} \mathrm{HCl}$ : ethanol mixture (50:50 vol \%) without electrochemistry before a next running cycle. The inset in (c) is SEM image of a cotton filter after $4 \mathrm{~h}$ of continuous operation. 


\subsection{Performance of the Cotton Filter towards TC Removal}

The $0.26 \mathrm{~mol} / \mathrm{h} / \mathrm{m}^{2}$ electrooxidation flux of MO in a single pass through the cotton filter is of note since the device was running under gravity feed. This also reveals the potential of a low-cost and energy-saving route for water purification. To further explore the potential for the treatment of other emerging organic contaminants, the as-fabricated conductive cotton filter was further challenged with a typical emerging contaminant, i.e., antibiotic tetracycline (TC, $0.2 \mathrm{mmol} / \mathrm{L}$ ). TC is one of the commonly detected antibiotics in water and the wastewater treatment plant was considered as one major point sources for TC pollution. Control experiments in the absence of applied cell potential can only adsorb physically the TC molecules until all sorption sites were occupied after $70 \mathrm{~min}$, i.e., adsorption saturation (Figure S5, Supplementary Materials). Figure 4a compares the TC electrooxidation flux as a function of total cell potential. The TC electrooxidation flux increased with increasing total cell potential from $1.0 \mathrm{~V}$ to $2.0 \mathrm{~V}$ with an electrooxidation flux of $0.9 \pm 0.1 \mathrm{~mol} / \mathrm{h} / \mathrm{m}^{2}$ for the cotton filter fabricated with a $1.5 \mathrm{mg} / \mathrm{mL}$ CNT ink. The TC electrooxidation flux changed negligibly with further increase in the total cell potential until $3.0 \mathrm{~V}$. This finding can be explained by the open-circuit measurements as displayed in Figure $4 \mathrm{~b}$. At a total cell potential of $1.5 \mathrm{~V}$, the anode potential was determined to be $0.7 \pm 0.06 \mathrm{~V}$ (vs. $\mathrm{Ag} / \mathrm{AgCl}$ ), which is high enough to oxide TC molecules (e.g., dimethylamine group of $\mathrm{TC}$ at $0.5 \mathrm{~V}$ vs. $\mathrm{Ag} / \mathrm{AgCl}$ ) [35]. It is of note that the maximum TC electrooxidation kinetics was $2.0 \mathrm{~V}$, which was quite different with that of MO. For example, an optimal total cell potential for MO electrooxidation was $3.5 \mathrm{~V}$, while only $2.0 \mathrm{~V}$ was required for TC electrooxidation. This finding could be explained by their different molecular structures and physicochemical properties. TC is an amphoteric molecule with multiple functional groups /moieties (e.g., phenol, amino, alcohol, diketone). Moreover, compared with MO, the TC molecules tend to adsorb onto the $s p^{2}$-conjugated CNT sidewalls due to its relatively strong van der Waals, $\pi-\pi$, and cation $-\pi$ interactions [35]. A recent report has demonstrated that TC has significant 3D molecular curvature and tend to adsorb onto the CNT surface until monolayer formation [35]. The LC-MS characterization results suggest that the characteristic TC peak observed in the influent solution was decreased by $63 \%$ and $96 \%$ at a total cell potential of $1.0 \mathrm{~V}$ and $2.0 \mathrm{~V}$, respectively, indicates that the parent TC molecules has been degraded. TC was spiked into real surface water samples to further challenge the cotton filter. The results show that the TC electrooxidation flux decreased by $35 \%$ compared with that of model electrolyte solution. The lower conductivity $(1408 \mu \mathrm{S} / \mathrm{cm}$ vs. $6289 \mu \mathrm{S} / \mathrm{cm})$ and complex natural reservoir organic matrix (background chemical oxygen demand, $\mathrm{COD}=47.1 \mathrm{mg} / \mathrm{L}$ ) may account for the significant decrease in electrooxidation kinetics. The energy consumption of the developed electrochemical cotton filter technology for TC treatment is calculated at an applied total cell potential of $2.0 \mathrm{~V}$, by assuming 31 electrons transferred per TC molecule, to be $1.2 \mathrm{kWh} / \mathrm{kg}$ COD (The COD used here is the theoretical COD). This value is comparative with state-of-the-art electrochemical oxidation processes with an energy consumption in the range of $5-100 \mathrm{kWh} / \mathrm{kg}$ COD [36-39]. Alternatively, the energy per volume treated is calculated to be only $0.05 \mathrm{kWh} / \mathrm{m}^{3}$. The gravity feed could further save the pumping energy which was constantly required for conventional membrane separation processes, especially for some high pressure-driven membrane separation process like RO. Of course, the energy consumed for MO electrooxidation should be higher than that of TC, since a larger total cell potential will be required to achieve efficient MO degradation (e.g., $3.5 \mathrm{~V}$ vs. $2.0 \mathrm{~V}$ ). The energy per MO volume treated is calculated to be $0.19 \mathrm{kWh} / \mathrm{m}^{3}, 3.7$ times higher than that of TC. The experimental results have demonstrated that the cotton filter clogging caused by the accumulation of precipitates/polymers may greatly limit the practical applications of the developed device towards the treatment of real water samples. Hence, further studies will be necessary to enhance the electrooxidative capability and to address the filter regeneration issues. Additionally, the ubiquitous presence of dissolved natural organic matters may negatively affect the efficacy and efficiency of the device toward practical applications. Since there are only limited active sites available on the cotton filter surface, the pollutant concentration effect on the device performance also deserves future investigation. Especially for the treatment of trace 
organic contaminants, e.g., antibiotic tetracycline, their environmental concentration should be taken into consideration in future studies.
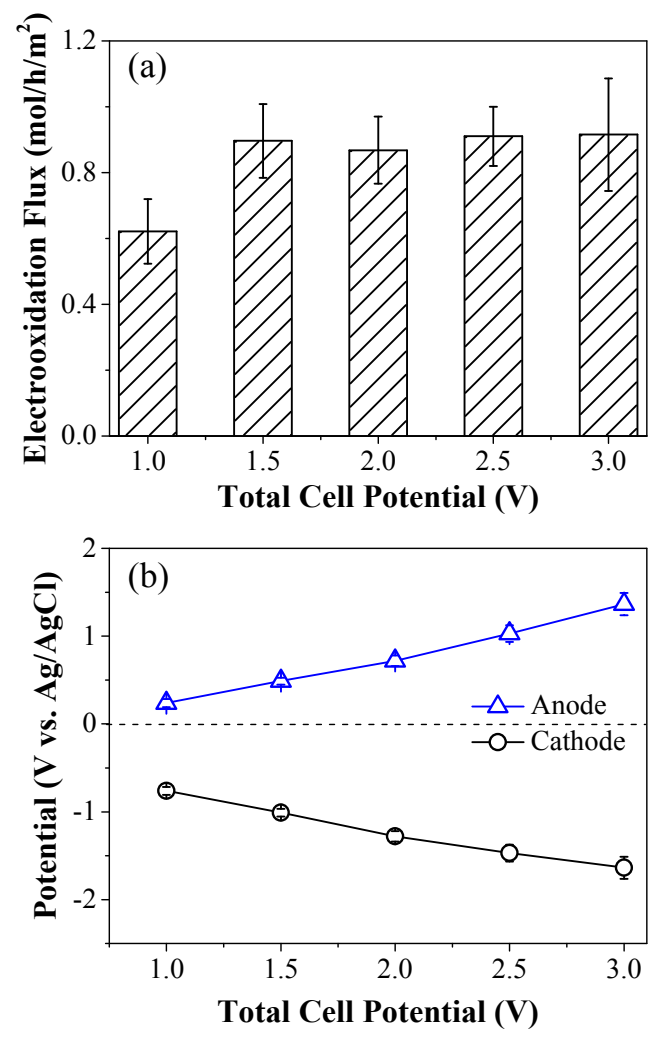

Figure 4. TC electrooxidation flux (a) and open-circuit potential (b) as a functional total cell potential. Experimental conditions: $[\mathrm{CNT}]_{\text {ink }}=1.5 \mathrm{mg} / \mathrm{mL},[\mathrm{TC}]_{\text {in }}=0.2 \mathrm{mmol} / \mathrm{L},\left[\mathrm{Na}_{2} \mathrm{SO}_{4}\right]=10 \mathrm{mmol} / \mathrm{L}$, and flow rate $=1.5 \mathrm{~mL} / \mathrm{min}$.

\section{Materials and Methods}

\subsection{Materials}

Multiwalled carbon nanotube networks (CNTs, $<\mathrm{d}>=15 \mathrm{~nm}$ and $<\mathrm{l}>=100 \mu \mathrm{m}$ ) were purchased from NanoTechLabs (Buckeye Composites, Yadkinville, NC, USA). Medical absorbent cottons were purchased from supermarket. Sodium sulfate $\left(\mathrm{Na}_{2} \mathrm{SO}_{4}, \geq 99.0 \%\right)$, methyl orange (MO, $\mathrm{C}_{14} \mathrm{H}_{14} \mathrm{~N}_{3} \mathrm{NaO}_{3} \mathrm{~S}$, ACS reagent, dye content $85 \%$ ), tetracycline (TC, $\mathrm{C}_{22} \mathrm{H}_{24} \mathrm{~N}_{2} \mathrm{O}_{8} \cdot \times \mathrm{H}_{2} \mathrm{O}, \geq 98.0 \%$ ), hydrochloric acid $(\mathrm{HCl}, \geq 37 \%$ ), ethanol (anhydrous, denatured), potassium hexacyanoferrate (II) trihydrate $\left(\mathrm{K}_{4} \mathrm{Fe}(\mathrm{CN})_{6} \cdot 3 \mathrm{H}_{2} \mathrm{O}\right)$, and sodium dodecyl benzene sulfonate (SDBS) were purchased from Sigma-Aldrich (St. Louis, MO, USA). Deionized water used in the experiments was produced by using a Milli-Q ultrapure water system (Millipore, Billerica, MA, USA).

\subsection{Fabrication of Conductive Cotton Filter}

Firstly, the CNT ink was prepared by adding a certain amount of CNTs $(0.5-1.5 \mathrm{mg} / \mathrm{mL})$ and a $10 \mathrm{mg} / \mathrm{mL}$ SDBS to deionized water. The mixture was then bath sonicated (KQ3200E bath sonicator, Kunshan, China) for $10 \mathrm{~min}$ and probe sonicated (Branson SFX150 sonifier, St. Louis, MO, USA) for another $15 \mathrm{~min}$ to improve the CNT dispensability in water. A facile dying method was used to load CNTs onto the cellulose fiber-based cotton samples. In a typical fabrication process, $100 \mathrm{mg}$ cotton sample was immersed into a freshly-prepared CNT ink for $5 \mathrm{~min}$, following $30 \mathrm{~min}$ of drying in an oven (at $120^{\circ} \mathrm{C}$ ). Before drying, the cotton sample was pressed with finger to remove extra SDBS surfactant until no visible bubbles were observed and washed with DI water. Due to the strong 
absorption capability, the CNT ink was quickly coated onto the cotton. By varying the 'dip-dry' cycles and CNT content in the ink, different amounts of CNTs can be loaded onto the cellulose fibers of cotton. We assume the CNT ink coated uniformly onto the cotton surface. The mass of the loaded CNTs can be obtained from the mass difference before and after the dipping and drying of the cotton samples. The loading of CNTs onto the cotton could significantly boost the electrical conductivity of the as-fabricated filter. Finally, the conductive cotton filters (with $2.0 \mathrm{~cm}$ in the funnel and $0.5 \mathrm{~cm}$ connect to the power supply) were transferred into a plastic funnel (bottom diameter of $0.8 \mathrm{~cm}$, funnel volume of $85 \mathrm{~mL}$ ) for electrochemical filtration applications.

\subsection{Electrochemical Filtration Device}

The electrochemical filtration experiments were conducted using a conductive cotton filter (with a length of $2.5 \mathrm{~cm})$ as anode, a Ti foil $\left(2 \times 5 \mathrm{~cm}\right.$ ) as cathode, and $10 \mathrm{mmol} / \mathrm{L} \mathrm{Na}_{2} \mathrm{SO}_{4}$ as background electrolyte. The solution passed through the conductive cotton filter by only gravity feed. In a typical experiment of electrochemical filtration of methyl orange (MO), $0.06 \mathrm{mmol} / \mathrm{L} \mathrm{MO}$, and $10 \mathrm{mmol} / \mathrm{L}$ $\mathrm{Na}_{2} \mathrm{SO}_{4}$ were first flowed through the filter in the absence of applied voltage to achieve adsorption saturation of the filter, which could exclude the contribution of physical sorption to pollutants removal. Unless noted, the volume treated was $200 \mathrm{~mL}$. Due to the limited space in the funnel, the solution was topped up every $15 \mathrm{~min}$ to maintain the 'driving force' (i.e., gravity). Then, an Agilent E3646A DC power supply was used to provide the voltage to induce the electro-oxidation of the pollutants. The effluent was collected at specific time intervals. Water flux was measured in a similar way by replacing the organic solution with $\mathrm{DI}-\mathrm{H}_{2} \mathrm{O}$. When challenging with the organic solution, the flux will decrease to some extent due to the accumulation of precipitates and/or polymers on the filter surface. To evaluate the regeneration performance of the conductive cotton filters, a $100 \mathrm{~mL}$ of ethanol and $1 \mathrm{~mol} / \mathrm{L} \mathrm{HCl}$ mixture (50:50 vol \%) was passed through the filter without electrochemistry after the MO electrochemical filtration. This could help to remove the organic residues from the filter surface. The oxidation flux was calculated by the Equation (2)

$$
\text { Elextrooxidation Flux }=\frac{\left(C_{\text {in }}-C_{\text {out }}\right)(\mathrm{mol} / \mathrm{L}) \times \text { flow rate }(\mathrm{L} / \mathrm{h})}{\text { effective filter area }\left(\mathrm{m}^{2}\right)}
$$

where $C_{\text {in }}$ is the initial influent compound concentration and $C_{\text {out }}$ is the compound concentration after passing through the cotton filter. The effluent samples were collected after applying the external potential for $20 \mathrm{~min}$. All these measurements were repeated at least three times for reproducibility.

\subsection{Characterizations}

The morphology of the as-fabricated conductive cotton filters was examined by a JEOL JSM-6700F filed-emission scanning electron microscopy (FESEM) (Carl Zeiss Supra55VP, Oberkochen, Germany). Micrographs were analyzed with ImageJ software (Bethesda, MD, USA) to get the average interfiber pore size of the as-fabricated filters, which was obtained from the average of at least 100 measurements from three FESEM images. The electrochemical characterizations of the samples were conducted on a CHI660E electrochemical workstation (Shanghai Chenhua Instrument Co. Ltd., Shanghai, China) using a three-electrode system. A conductive cotton filter, an $\mathrm{AgCl} / \mathrm{Ag}$ electrode and a Ti foil served as working electrode, reference electrode and counter electrode, respectively. For the open-circuit voltage measurements, an Agilent E3646A DC power (Santa Clara, CA, USA) supply was used to provide an applied voltage of 0 to $4 \mathrm{~V}$. The concentration of ferricyanide and methyl orange (MO) was determined by a Shimadzu UV-1800 UV-vis photometer (Kyoto, Japan) at their maximum absorbance values of $425 \mathrm{~nm}$ and $462 \mathrm{~nm}$, respectively. The concentration of tetracycline (TC) was determined by using an Agilent 1290 UHPLC system (Waldbronm, Germany) coupled with 6540 quadrupole-time of flight (Q-TOF) mass detector equipped with a dual jet stream electrospray ionization source. 


\section{Conclusions}

In conclusion, an affordable and effective electrochemical cotton-based filtration device for water treatment was developed. The CNT amount, total cell potential and surfactant were identified to be key parameters affecting the device performance. Moreover, the efficient electrooxidation of ferrocyanide, methyl orange, and antibiotic tetracycline suggest that the electrochemical cotton filters have good potential for water purification applications. Overall, the experiment results presented in this study quantitatively exemplified the advantages of a conductive cotton filter for water purification in a low-cost and energy-saving manner.

Supplementary Materials: The following are available online at www.mdpi.com/2073-4344/7/10/291/s1; Figure S1: FESEM images of conductive cotton filters fabricated using $[\mathrm{CNT}]_{\text {ink }}=1.5 \mathrm{mg} / \mathrm{mL}$; Figure S2: Variation of filter resistance of as-fabricated cotton filters with CNT ink concentrations; Figure S3: Demonstration of a CNT cotton filter acts as a conducting path in the emission of an LED indicative lamp under applied voltage of $4 \mathrm{~V}$; Figure S4: MO breakthrough curve under conditions of $[\mathrm{MO}]_{\text {in }}=0.06 \mathrm{mmol} / \mathrm{L},\left[\mathrm{Na}_{2} \mathrm{SO}_{4}\right]=10 \mathrm{mmol} / \mathrm{L}$, and flow rate $=1.5 \mathrm{~mL} / \mathrm{min}$; Figure S5. TC breakthrough curves under conditions of $[\mathrm{TC}]_{\text {in }}=0.2 \mathrm{mmol} / \mathrm{L},\left[\mathrm{Na}_{2} \mathrm{SO}_{4}\right]=$ $10 \mathrm{mmol} / \mathrm{L}$, and flow rate $=1.5 \mathrm{~mL} / \mathrm{min}$.

Acknowledgments: This work was financially supported by the National Natural Science Foundation of China (No.51478099 and No. 51208206) and National Key Research and Development Program of China (No. 2016YFC0400501). Y.L. thanks Donghua University for the start-up grant (No. 113-07-005710).

Author Contributions: F.L. and Y.B.L. conceived and designed the experiments; Q.X. and Q.C. performed the experiments; M.Z.H. and Q.X. analyzed the data; Y.B.L. wrote the paper.

Conflicts of Interest: The authors declare no conflict of interest.

\section{References}

1. Zodrow, K.R.; Li, Q.; Buono, R.M.; Chen, W.; Daigger, G.; Dueñas-Osorio, L.; Elimelech, M.; Huang, X.; Jiang, G.; Kim, J.-H.; et al. Advanced materials, technologies, and complex systems analyses: Emerging opportunities to enhance urban water security. Environ. Sci. Technol. 2017, 51, 10274-10281. [CrossRef] [PubMed]

2. Zhang, R.; Liu, Y.; He, M.; Su, Y.; Zhao, X.; Elimelech, M.; Jiang, Z. Antifouling membranes for sustainable water purification: Strategies and mechanisms. Chem. Soc. Rev. 2016, 45, 5888-5924. [CrossRef] [PubMed]

3. Madaeni, S.S.; Ghaemi, N.; Rajabi, H. 1-Advances in Polymeric Membranes for Water Treatment, in Advances in Membrane Technologies for Water Treatment; Woodhead Publishing: Oxford, UK, 2015; pp. 3-41.

4. Liu, Y.; Zhang, Y.; Wang, L.; Yang, G.; Shen, F.; Deng, S.; Zhang, X.; He, Y.; Hu, Y.; Chen, X. Fast and large-scale anodizing synthesis of pine-cone $\mathrm{TiO}_{2}$ for solar-driven photocatalysis. Catalysts 2017, 7, 229. [CrossRef]

5. O'Shea, K.E.; Dionysiou, D.D. Advanced oxidation processes for water treatment. J. Phys. Chem. Lett. 2012, 3, 2112-2113. [CrossRef]

6. Deng, Y.; Zhao, R. Advanced oxidation processes (AOPs) in wastewater treatment. Curr. Pollution Rep. 2015, 1, 167-176. [CrossRef]

7. Lazar, M.; Varghese, S.; Nair, S. Photocatalytic water treatment by titanium dioxide: Recent updates. Catalysts 2012, 2, 572-601. [CrossRef]

8. Santos, M.C.; Elabd, Y.A.; Jing, Y.; Chaplin, B.P.; Fang, L. Highly porous $\mathrm{Ti}_{4} \mathrm{O}_{7}$ reactive electrochemical water filtration membranes fabricated via electrospinning/electrospraying. AIChE J. 2016, 62, 508-524. [CrossRef]

9. Ikehata, K.; Jodeiri Naghashkar, N.; Gamal El-Din, M. Degradation of aqueous pharmaceuticals by ozonation and advanced oxidation processes: A review. Ozone Sci. Eng. 2006, 28, 353-414. [CrossRef]

10. Kim, K.-J.; Jang, A. Fouling characteristics of NOM during the ceramic membrane microfiltration process for water treatment. Desalination Water Treat. 2016, 57, 9034-9042. [CrossRef]

11. Chaplin, B.P. Critical review of electrochemical advanced oxidation processes for water treatment applications. Environ. Sci. Process. Impacts 2014, 16, 1182-1203. [CrossRef] [PubMed]

12. Anglada, Á.; Urtiaga, A.; Ortiz, I. Contributions of electrochemical oxidation to waste-water treatment: Fundamentals and review of applications. J. Chem. Technol. Biotechnol. 2009, 84, 1747-1755. [CrossRef]

13. Chen, G. Electrochemical technologies in wastewater treatment. Sep. Purif. Technol. 2004, 38, 11-41. [CrossRef]

14. Popov, V.N. Carbon nanotubes: Properties and application. Mater. Sci. Eng. R 2004, 43, 61-102. [CrossRef] 
15. Wu, J.; Gerstandt, K.; Zhang, H.; Liu, J.; Hinds, B.J. Electrophoretically induced aqueous flow through single-walled carbon nanotube membranes. Nat. Nanotechnol. 2012, 7, 133-139. [CrossRef] [PubMed]

16. De Volder, M.F.L.; Tawfick, S.H.; Baughman, R.H.; Hart, A.J. Carbon nanotubes: Present and future commercial applications. Science 2013, 339, 535-539. [CrossRef] [PubMed]

17. Liu, Y.; Zheng, Y.; Du, B.; Nasaruddin, R.R.; Chen, T.; Xie, J. Golden carbon nanotube membrane for continuous flow catalysis. Ind. Eng. Chem. Res. 2017, 56, 2999-3007. [CrossRef]

18. Liu, H.; Zuo, K.; Vecitis, C.D. Titanium dioxide-coated carbon nanotube network filter for rapid and effective arsenic sorption. Environ. Sci. Technol. 2014, 48, 13871-13879. [CrossRef] [PubMed]

19. Gao, G.; Zhang, Q.; Hao, Z.; Vecitis, C.D. Carbon nanotube membrane stack for flow-through sequential regenerative electro-Fenton. Environ. Sci. Technol. 2015, 49, 2375-2383. [CrossRef] [PubMed]

20. Liu, Y.; Xie, J.; Ong, C.N.; Vecitis, C.D.; Zhou, Z. Electrochemical wastewater treatment with carbon nanotube filters coupled with in situ generated $\mathrm{H}_{2} \mathrm{O}_{2}$. Environ. Sci. Water Res. Technol. 2015, 1, 769-778. [CrossRef]

21. Gui, X.; Wei, J.; Wang, K.; Cao, A.; Zhu, H.; Jia, Y.; Shu, Q.; Wu, D. Carbon Nanotube Sponges. Adv. Mater. 2010, 22, 617-621. [CrossRef] [PubMed]

22. Li, X.; Xue, Y.; Zou, M.; Zhang, D.; Cao, A.; Duan, H. Direct oil recovery from saturated carbon nanotube sponges. ACS Appl. Mater. Interfaces 2016, 8, 12337-12343. [CrossRef] [PubMed]

23. Schoen, D.T.; Schoen, A.P.; Hu, L.; Kim, H.S.; Heilshorn, S.C.; Cui, Y. High speed water sterilization using one-dimensional nanostructures. Nano Lett. 2010, 10, 3628-3632. [CrossRef] [PubMed]

24. Arash, B.; Wang, Q.; Varadan, V.K. Mechanical properties of carbon nanotube/polymer composites. Sci. Rep. 2014, 4, 6479. [CrossRef] [PubMed]

25. Makowski, T.; Kowalczyk, D.; Fortuniak, W.; Jeziorska, D.; Brzezinski, S.; Tracz, A. Superhydrophobic properties of cotton woven fabrics with conducting 3D networks of multiwall carbon nanotubes, MWCNTs. Cellulose 2014, 21, 4659-4670. [CrossRef]

26. Pasta, M.; La Mantia, F.; Hu, L.; Deshazer, H.D.; Cui, Y. Aqueous supercapacitors on conductive cotton. Nano Res. 2010, 3, 452-458. [CrossRef]

27. Wang, Z.; Huang, Y.; Sun, J.; Huang, Y.; Hu, H.; Jiang, R.; Gai, W.; Li, G.; Zhi, C. Polyurethane/Cotton/Carbon Nanotubes Core-Spun Yarn as High Reliability Stretchable Strain Sensor for Human Motion Detection. ACS Appl. Mater. Interfaces 2016, 8, 24837-24843. [CrossRef] [PubMed]

28. Islam, M.F.; Rojas, E.; Bergey, D.M.; Johnson, A.T.; Yodh, A.G. High weight fraction surfactant solubilization of single-wall carbon nanotubes in water. Nano Lett. 2003, 3, 269-273. [CrossRef]

29. Qi, H.; Liu, J.; Mäder, E. Smart cellulose fibers coated with carbon nanotube networks. Fibers 2014, 2, 295. [CrossRef]

30. Rahman, M.J.; Mieno, T. Conductive cotton textile from safely functionalized carbon nanotubes. J. Nanomater. 2015, 2015. [CrossRef]

31. Liu, H.; Liu, J.; Liu, Y.; Bertoldi, K.; Vecitis, C.D. Quantitative 2D electrooxidative carbon nanotube filter model: Insight into reactive sites. Carbon 2014, 80, 651-664. [CrossRef]

32. Liu, Y.; Dustin Lee, J.H.; Xia, Q.; Ma, Y.; Yu, Y.; Lanry Yung, L.Y.; Xie, J.; Ong, C.N.; Vecitis, C.D.; Zhou, Z. A graphene-based electrochemical filter for water purification. J. Mater. Chem. A 2014, 2, 16554-16562. [CrossRef]

33. Vecitis, C.D.; Gao, G.; Liu, H. Electrochemical carbon nanotube filter for adsorption, desorption, and oxidation of aqueous dyes and anions. J. Phys. Chem. C 2011, 115, 3621-3629. [CrossRef]

34. Gao, G.; Pan, M.; Vecitis, C.D. Effect of the oxidation approach on carbon nanotube surface functional groups and electrooxidative filtration performance. J. Mater. Chem. A 2015, 3, 7575-7582. [CrossRef]

35. Liu, Y.; Liu, H.; Zhou, Z.; Wang, T.; Ong, C.N.; Vecitis, C.D. Degradation of the common aqueous antibiotic tetracycline using a carbon nanotube electrochemical filter. Environ. Sci. Technol. 2015, 49, 7974-7980. [CrossRef] [PubMed]

36. Avlonitis, S.A.; Kouroumbas, K.; Vlachakis, N. Energy consumption and membrane replacement cost for seawater RO desalination plants. Desalination 2003, 157, 151-158. [CrossRef]

37. Lee, Y.; Gerrity, D.; Lee, M.; Gamage, S.; Pisarenko, A.; Trenholm, R.A.; Canonica, S.; Snyder, S.A.; von Gunten, U. Organic contaminant abatement in reclaimed water by $\mathrm{UV} / \mathrm{H}_{2} \mathrm{O}_{2}$ and a combined process consisting of $\mathrm{O}_{3} / \mathrm{H}_{2} \mathrm{O}_{2}$ followed by $\mathrm{UV} / \mathrm{H}_{2} \mathrm{O}_{2}$ : Prediction of abatement efficiency, energy consumption, and byproduct formation. Environ. Sci. Technol. 2016, 50, 3809-3819. [CrossRef] [PubMed] 
38. Zou, S.; Yuan, H.; Childress, A.; He, Z. Energy consumption by recirculation: A missing parameter when evaluating forward osmosis. Environ. Sci. Technol. 2016, 50, 6827-6829. [CrossRef] [PubMed]

39. Xiao, H.; Wu, M.; Zhao, G. Electrocatalytic oxidation of cellulose to gluconate on carbon aerogel supported gold nanoparticles anode in alkaline medium. Catalysts 2016, 6, 5. [CrossRef] 